\title{
Genitourinary system trauma after 2003 Bam earthquake in Kerman, Iran
}

\author{
This article was published in the following Dove Press journal: \\ Therapeutics and Clinical Risk Management \\ I0 February 201I \\ Number of times this article has been viewed
}

\section{Mohammad Hasan \\ Dehghani Firoozabadi \\ Mehdi Abedinzadeh ${ }^{2}$ \\ Mohammad Kazem \\ Moslemi ${ }^{3}$}

'Department of Urology, Neuroscience Research Center, Kerman University of Medical Sciences, Kerman, Iran; ${ }^{2}$ Department of Urology, Moradi Hospital, School of Medicine, Rafsanjan University of Medical Sciences, Rafsanjan, Iran; ${ }^{3}$ Department of Urology, Kamkar Hospital, School of Medicine, Qom University of Medical Sciences, Qom, Iran
Correspondence: Mohammad Kazem Moslemi

Department of Urology, Kamkar Hospital, School of Medicine, Qom University of Medical Sciences,

Qom, Iran

Tel +98912 2521646

Fax +98 25I 77I 3473

Email mkmoslemi@gmail.com
Background: Natural disasters, especially earthquakes, result in many health problems all over the world, of which urological injuries should not be underestimated. Car accidents and falling from a height are the most common causes of genitourinary system injury. The lack of specific data in the literature regarding the outcome of earthquake-related genitourinary system trauma prompted us to undertake this study.

Methods: We retrospectively evaluated the genitourinary system injury in patients who had survived the Bam earthquake. In this study, all patients admitted to two main back-up hospitals of Kerman were included. Of 256 patients who had been referred to Kerman hospitals, 28 cases were found to have urologic damage on physical examination, intravenous pyelography, abdominopelvic X-ray, and ultrasonography.

Results: Of 28 patients with urologic damage, 22 (78.5\%) were male and six $(21.5 \%)$ were female. Their age ranged from 18 to 65 years. The injures included urethral disruption in 21 cases $(75.5 \%)$, vesicovaginal fistula in four cases (14\%), kidney rupture in two cases $(7 \%)$ and bladder neck disruption accompanied with total right ureteral disruption and vesicovaginal fistula in a female patient (3.5\%).

Conclusion: We have evaluated the incidence of genitourinary injuries after an earthquake disaster for the first time. The most and least common urologic injury in our patients was urethral disruption and ureteral injury, respectively.

Keywords: earthquake, urethral injury, trauma, genitourinary system, renal injury, emergency department

\section{Introduction}

Natural disasters are ecological phenomena that disturb the normal order of life in a society beyond its adaptive capabilities, and thus result in an urgent and great necessity for external aid. Compared with other natural disasters, earthquakes are much more harmful, causing both loss of life and material losses. ${ }^{1,2}$ Earthquake magnitude is evaluated by the Richter scale. It was developed in 1935 by Charles Richter in collaboration with Beno Gutenberg, both of the California Institute of Technology. This scale assigns a single number to quantify the amount of seismic energy released by an earthquake. The magnitude of an earthquake is determined from the logarithm of the amplitude of waves recorded by seismographs. On the Richter scale, magnitude is expressed in whole numbers and decimal fractions. For example, a magnitude 5.3 might be computed for a moderate earthquake, and a strong earthquake might be rated as magnitude $6.3 .3,4$

An earthquake measuring 6.6 on the Richter scale struck the city of Bam and the surrounding areas of Kerman Province, southeastern Iran, on December 26, 2003 
at 5:26 am (Iran standard time). It was a disaster in which the city was destroyed, with over 40,000 people killed and nearly 30,000 injured. ${ }^{5}$ Before the 2003 earthquake, the official population count of the city was roughly $43,000{ }^{6}$ The modern city of Bam surrounds the Bam citadel. It was developed as an agricultural and industrial center, and until the 2003 earthquake was experiencing rapid growth. The city is known for its dates and citrus fruit, and has benefited from tourism due to its ancient citadel. ${ }^{7}$ It is well known that Iran is an earthquake-prone country. However, this urban earthquake was a new event because the populous of the older city of Bam was involved. The management capacity of the regular emergency medical care system was exceeded during this earthquake because main roads, lifelines, (including water, gas, electricity), and many hospitals were severely damaged. The aim of this research was to document genitourinary system injury patterns following an earthquake.

\section{Materials and methods}

We retrospectively evaluated urological trauma in patients who survived the Bam earthquake. Participants consisted of all patients with multiple traumas who were admitted to two major Kerman hospitals (Hazrat-e-Fatemeh and Kashani). Although more than 30,000 casualties were estimated, the main injuries were minor, and those cases were managed in the emergency room on an outpatient basis. Other cases needing admission were transferred to neighboring provinces. Medical records and patient imaging studies were carefully reviewed in order to determine their initial urological status (at the time of primary hospital admission) and associated injuries. A total of 256 cases with earthquake-related injuries were referred to the two tertiary hospitals of Kerman within the first 72 hours after the disaster. After full physical examination, radiographic evaluation, intravenous pyelography, retrograde urethrography, and/or cystography, 28 cases (11\%) of genitourinary trauma were detected and enrolled in our study (Table 1). The data collected included demographic characteristics, mechanism of trauma, type and severity of injury, associated injuries, detection of abnormal radiologic

Table I Characteristics of patients admitted after the Bam earthquake in Iran

Admitted cases (total) 256 cases

$28(\mathrm{I} I \%) \rightarrow$ Selected cases with genitourinary trauma

M/F 22/6

Male $78.5 \%$

Female $11.5 \%$

Age, years mean (range) 47 (18-67)

Mean hospital stay (days) 4 (2-14) findings, and intraperitoneal or extraperitoneal rupture on cystography. The data collected were analyzed with SPSS software (SPSS Inc, Chicago, IL).

\section{Results}

Of 256 patients admitted to the aforementioned hospitals due to the earthquake, 28 had genitourinary system trauma alone or in combination with other organ system trauma, comprising $11 \%$ of the total hospitalized trauma patients. Twenty-two cases $(78.5 \%)$ were males and six $(11.5 \%)$ were females. The mean age of those admitted was 47 (18-67) years (Table 1). All of the patients were in the supine position at the time of the earthquake. After full radiographic evaluation with abdominopelvic computed tomography, cystography, and retrograde urethrography, the most commonly diagnosed injury was pelvic fracture accompanied by urethral disruption (PFUD, 10 cases $[35.5 \%]$ ), urethral disruption or injury alone in 10 cases $(35.5 \%)$, and PFUD synchronous with liver injury in one case (3.5\%). In the remainder, there were four cases (14\%) of vesicovaginal fistula, two cases $(7 \%)$ of renal shattering or simple injury cases, and one case $(3.5 \%)$ of bladder neck rupture with synchronous right ureteral disruption (Table 2). The most common signs and symptoms in these cases were urethrorrhagia and inability to void, with or without signs and symptoms of pelvic bone fracture. All of the cases with PFUD and urethral disruption occurred in males $(P \leq 0.05)$. There were no female urethral injuries identified.

There was no difference regarding age of the patients and type of injuries observed $(P \leq 0.05)$. The treatment selected for urethral injury with or without pelvic fracture was open or percutaneous cystostomy and urethral repair performed 3-6 months after the primary admission. In the case of renal shattering (Grade 5, one case [3.5\%]), simple nephrectomy was performed. A case of Grade 3 renal trauma in a woman was managed conservatively. One case of vesicovaginal fistula was treated 2-4 weeks after primary admission. The mean primary hospital stay was four (2-14) days.

Table 2 Prevalence of specific injuries

\begin{tabular}{lll}
\hline Type of injury & $\begin{array}{l}\text { Number } \\
\text { (28 cases) }\end{array}$ & $\begin{array}{l}\text { Percentage } \\
\mathbf{( 1 0 0 \% )}\end{array}$ \\
\hline Pelvic fracture-urethral disruption & 10 cases & $36 \%$ \\
Urethral disruption & 10 cases & $36 \%$ \\
Vesicovaginal fistula & 4 cases & $14 \%$ \\
Renal trauma & 2 cases & $7 \%$ \\
Right ureteral rupture with & I case & $3.5 \%$ \\
synchronous vesicovaginal fistula & & \\
Pelvic fracture-urethral disruption & I case & $3.5 \%$ \\
associated with liver injury & & \\
\hline
\end{tabular}


After performance of temporizing measures like cystostomy, and treatment of related orthopedic injuries, the patients were followed up in the usual manner.

\section{Discussion}

Over 500,000 earthquakes are reported each year worldwide. However, the majority are minor events, with only a minority resulting in significant morbidity and mortality. ${ }^{8}$ Earthquakes are the most destructive of the natural disasters, with three million lives claimed over the past 20 years. ${ }^{9}$ Based on our study, the most common urologic injury sustained in the supine position after earthquake was urethral disruption. In earthquake-induced trauma, however, each body part can be traumatized separately under different loads with different forces. Thus, each injury is independent from the others. ${ }^{5}$ In our cases, collapsed dwellings contributed to almost all of the injuries. Most injured persons were indoors at the time, asleep in old clay houses. In a study by Mulvey et al, 149 cases admitted after the 2005 Kashmir earthquake were evaluated. ${ }^{10}$ The most common injuries (50\%) were to the lower and/or upper extremities. Abdominal injuries were reported in $1 \%$ of cases. No cases of renal trauma or other genitourinary injuries were reported. In a study by Bulut et al of 263 Marmara earthquake patients in 1999, the most frequently occurring injuries among the hospitalized trauma patients were to the extremities (66.6\%), followed by spinal, chest, and abdominal $(7.1 \%)$, and cranial and pelvic (4.5\%) injuries.

In the nonearthquake-related trauma patients, up to $10 \%$ have been reported to have involvement of the urogenital system, and $10 \%-15 \%$ of trauma patients with abdominal injuries have urogenital involvement. ${ }^{11}$ Kidney injuries constitute $45 \%$ of all urogenital traumas, and the most common cause is blunt trauma. Bladder injuries are most commonly caused by pelvic fractures. In $5 \%-10 \%$ of cases with pelvic fractures, urinary tract injuries have been detected. ${ }^{12,13}$

We observed that the chance of earthquake-related urogenital system trauma was higher than for nonearthquake-related trauma, and its pattern differed. In a study by Salimi et al of 17,753 nonearthquake-related trauma admissions, nearly $1 \%$ had injuries to the urogenital system. ${ }^{14}$ We found urogenital trauma in $11 \%$ of our earthquake patients. Road traffic accident was the most common cause of trauma, and the most commonly injured organs were the kidneys in $61.1 \%$ of cases and the bladder in $13.7 \%$, whereas urethral injury was the most commonly injured site. Associated intra-abdominal injuries were detected in $74 \%$ of cases. In addition, urethral injuries were detected in $8.6 \%$ of cases, but after the earthquake we found earthquake-related injuries in $74.5 \%$ of our cases.
When earthquakes occur in countries with modern buildings, such as the US or Japan, casualties are thought to be caused by the failure of nonstructural elements or by earthquake-induced accidents, rather than by the collapse of buildings, ${ }^{15}$ as occurred in Bam. Crush syndrome or injuries to the vital organs are the main cause of morbidity and mortality in earthquakes. ${ }^{16}$ We did not find crush syndrome in any of our cases. In a study by Tanaka et al after the 1995 Hanshin-Awaji earthquake in Japan involving 2718 cases, ${ }^{17}$ 67 abdominal injuries and 338 pelvic fractures were reported. No information on the genitourinary system was reported. In earthquake-induced trauma, each body part can be traumatized separately under different loads with different forces. Thus, each injury is independent from the others, ${ }^{5}$ which was also true in our study.

\section{Conclusion}

Catastrophes can occur anywhere and at any time, and the number of victims cannot be foreseen. Following a devastating catastrophe, such as an earthquake, especially during the initial 24-48-hour period, an excessive flow of patients will always be encountered in emergency departments. Evaluation of these patients by specialized and complementary teams is important.

We focused for the first time on genitourinary injuries after an earthquake, and found that urethral disruption injuries are most common, and urgent cystostomy is a temporizing measure.

\section{Disclosure}

The authors report no conflicts of interest in this work.

\section{References}

1. Mahoney LE, Reutershan TP. Catastrophic disasters and the design of disaster medical care systems. Ann Emerg Med. 1987;16:1085-1091.

2. Building Seismic Safety Council. Seismic Considerations: Health care facilities. FEMA 150. Washington, DC: Federal Emergency Management Agency Publication, 1990.

3. Ellsworth WL. The Richter Scale (ML). 1991. Available at: http:// www.johnmartin.com/earthquakes/eqsafs/safs_693.htm. Accessed September 14, 2010.

4. US Geological Survey. The Richer Magnitude Scale. Available at: http://earthquake.usgs.gov/learn/topics/richter.php. Accessed on May 5, 2010

5. Karamouzain S, Saeed A, Ashraf-Ganjouei K, Ebrahiminejad A, Dehghani MR, Asadi AR. The neurological outcome of spinal cord injured victims of the Bam earthquake, Kerman, Iran. Arch Iran Med. 2010;13:351-354

6. Moszynski P. Cold is the main health threat after the Bam earthquake. BMJ. 2004;328:66.

7. Wikipedia. Bam, Iran. Available at: http://en.wikipedia.org/wiki/ Bam,_Iran. Accessed January 17, 2011.

8. Alexander D. The health effects of earthquakes in the mid 1990s. Disasters. 1996;20:231-247. 
9. Bulut M, Fedakar R, Akkose S, et al. Medical experience of a university hospital in Turkey after the 1999 Marmara earthquake. Emerg Med J. 2005;22:494-498.

10. Mulvey JM, Awan SU, Qadri AA, Maqsood MA. Profile of injuries arising from the $2005 \mathrm{Kashmir}$ earthquake: The first $72 \mathrm{~h}$. Injury. 2008; 39:554-560

11. Dandan IS, Farhat W. Trauma, upper urogenital. Available at: http:// emedicine.medscape.com/article/828154-overview. Accessed January 17, 2011.

12. Kuo RL, Eachempati SR, Makhuli MJ, Reed RL 2nd. Factors affecting management and outcome in blunt renal injury. World J Surg. 2002; 26:416-419.

13. Hsieh CH, Chen RJ, Fang JF, et al. Diagnosis and management of bladder injury by trauma surgeons. Am J Surg. 2002;184:143-147.
14. Salimi J, Nikoobakht MR, Khaji A. Epidemiology of urogenital trauma: Results of the Iranian National Trauma Project. Urol J. 2006; 3:171-174.

15. Coubran AW, Ohashi H, Ohta Y. Factors affecting fatalities and injury in earthquakes. In: Engineering Seismology and Earthquake Disaster Prevention Planning. Internet Report. Hokkaido, Japan: Hokkaido University; 1987.

16. Kuwagata Y, Oda J, Tanaka H, et al. Analysis of 2,702 traumatized patients in the 1995 Hanshin-Awaji earthquake. J Trauma. 1997; 43:427-432.

17. Tanaka H, Oda J, Iwai A, et al. Morbidity and mortality of hospitalized patients after the 1995 Hanshin-Awaji earthquake. Am J Emerg Med. 1999;17:186-191.

\section{Publish your work in this journal}

Therapeutics and Clinical Risk Management is an international, peerreviewed journal of clinical therapeutics and risk management, focusing on concise rapid reporting of clinical studies in all therapeutic areas, outcomes, safety, and programs for the effective, safe, and sustained use of medicines. This journal is indexed on PubMed Central, CAS,
EMBase, Scopus and the Elsevier Bibliographic databases. The manuscript management system is completely online and includes a very quick and fair peer-review system, which is all easy to use. Visit http://www.dovepress.com/testimonials.php to read real quotes from published authors.

Submit your manuscript here: http://www.dovepress.com/therapeutics-and-clinical-risk-management-journal 